\title{
Ochratoxin A occurrence and formation in Portuguese wine grapes at various stages of maturation
}

\author{
R. Serra, C. Mendonça, A. Venâncio * \\ Centro de Engenharia Biológica, Universidade do Minho, Campus de Gualtar, 4710-057 Braga, Portugal
}

\begin{abstract}
A total of 93 Portuguese grape samples destined for wine production were examined for the presence of ochratoxin A (OTA) and the OTA producing fungi Aspergillus carbonarius and A. niger aggregate. Samples came from 11 vineyards from four winemaking regions in the North and South of the Portuguese mainland, during the harvest seasons of 2001, 2002 and 2003. Grapes were examined at 3 maturation stages, from setting to the harvesting period, to evaluate when contamination with OTA producing fungi and OTA synthesis occur. The detection of fungi in grape samples was made by plating methods with and without surface disinfection. OTA was formed by $14 \%$ of the 650 isolates tested. Most of the OTA producing strains $(96 \%)$ were isolated at harvest time. At this stage, the percentage of grape samples with OTA producing strains detected without surface disinfection was $56 \%$. With surface disinfection, $A$. carbonarius was isolated from $10 \%$ of the samples. OTA was detected in grapes at the 3 maturation stages. The average OTA concentrations in 60 samples at pea berry ( 28 samples), early veraison ( 22 samples) and ripe berry ( 20 samples) were 263, 149 and $35 \mathrm{ng} / \mathrm{kg}$, respectively. Experiments with an A. carbonarius strain demonstrated that OTA production differs significantly with the composition of the berries at different maturation stages $(P<0.001)$, with a mean value of OTA production at pea berry, early veraison and ripe berry of 3402, 1530 and $22 \mu \mathrm{g} / \mathrm{kg}$, respectively. The production of OTA by $A$. carbonarius was correlated positively and negatively with the total acidity of grapes $\left(r_{\mathrm{s}}=0.855, P<0.001\right)$ and reducing sugars content $\left(r_{\mathrm{s}}=-0.835, P<0.001\right)$, respectively. Our data demonstrate that OTA synthesis in grapes occurs since early maturation stages.
\end{abstract}

(C) 2006 Elsevier B.V. All rights reserved.

Keywords: A. carbonarius; A. niger aggregate; Grapes; Mycotoxins; Ochratoxin A; Wine

\section{Introduction}

Ochratoxin A (OTA) is a mycotoxin with nephrotoxic, nephrocarcinogenic, teratogenic and immunosuppressive properties, which recently has received a great deal of interest from the scientific community (Battaglia et al., 1996; Walker, 1999). It has been detected in foods and beverages, including grape juice and wine, where it was reported for the first time by Zimmerli and Dick (1995). Since then, surveys conducted in different countries have revealed the presence of OTA in these foods and beverages (Burdaspal and Legarda, 1999; Otteneder and Majerus, 2000; Pietri et al., 2001; Ratola et al., 2004; Soufleros et al., 2003; Stefanaki et al., 2003; Zimmerli and Dick, 1996). A European report estimated that wine is the second major source of OTA intake in European populations (Miraglia and Brera, 2002). A maximum limit for OTA in wine

\footnotetext{
* Corresponding author. Tel.: +351 253604413; fax: +351 253678986
}

E-mail address: avenan@deb.uminho.pt (A. Venâncio). of $2 \mu \mathrm{g} / \mathrm{kg}$ was regulated in the $\mathrm{EU}$, and a recommendation to lower OTA levels to the lowest technologically feasible level was made. Therefore, it is essential to know the situation in each member country in order to define a concerted plan to minimize its occurrence.

A survey showed that Aspergillus carbonarius and occasionally $A$. niger are the OTA sources in Portuguese wine grapes (Serra et al., 2003, 2005). In these studies, A. niger aggregate and $A$. carbonarius represented $88 \%$ and $12 \%$ of the black Aspergillus isolated strains, respectively. In each of the mentioned species, $4 \%$ and $89 \%$ of the strains were OTA positive, respectively. However, A. carbonarius cultures where OTA was not detected are now regarded as a new species: Aspergillus ibericus (Serra et al., in press). Furthermore, the mycotoxin was detected in grapes before and at harvest time (Battilani et al., 2003; Serra et al., 2004), indicating that some OTA contamination occurs preharvest. Several factors have been suggested as relevant to OTA contamination of wine grapes (Battilani et al., 2003). The effects of temperature and 
water activity on growth and OTA production by $A$. carbonarius and $A$. niger strains have been investigated (Belli et al, 2004; Mitchell et al., 2004). However, there are no studies on the influence of grape variety and maturation stage on OTA formation.

The work presented here was carried out to study (i) the 3year distribution of OTA producing fungi in wine grapes from early maturation stages to ripe berry; (ii) to evaluate the presence of OTA in Portuguese wine grapes; (iii) the influence of the composition of grapes (different varieties at different maturation stages) on OTA producing ability by ochratoxigenic fungi; (iv) to contribute for the establishment of the critical control points for OTA synthesis in grapes.

\section{Materials and methods}

\subsection{Winemaking regions and sampling}

The study area and sampling plans were described previously (Serra et al., 2003). Four winemaking regions and 11 vineyards were studied: Vinhos Verdes (vineyards 1 to 3 ), Douro (4 to 6), Ribatejo (7 to 9) and Alentejo (10 and 11). For the 3-year distribution of OTA producing fungi in grapes, grapes were collected from June to September of 2001, 2002 and 2003, at 3 developmental stages of the berries - pea berry (June/July -29 samples), early veraison (July/August - 33 samples), and ripe berry (August/September - 31 samples). From these samples, 26 were collected in Vinhos Verdes, 27 in Douro, 27 in Ribatejo, and 13 in Alentejo. Collection date was determined according the information of the maturation stages provided by the viticulturists. At each sampling time in each vineyard, ten bunches were collected.

Fifteen of the samples collected in 2002 (4 at pea berry, 6 at early veraison, and 5 at ripe berry) were used to evaluate the influence of grapes in OTA production.

\subsection{Mycological analysis of the grapes}

The individual samples as defined above were composed of 50 berries, plated on Dichloran Rose Bengal Chloramphenicol medium (DRBC, Oxoid, Basingstoke, Hampshire, England) 5 berries per plate, as previously described (Serra et al., 2003). Additionally, other sets of 50 berries each were surface disinfected as described by Pitt and Hocking (1997) by immersing the berries in a chlorine solution for $2 \mathrm{~min}$ to assess fungal infection at harvest time in the harvest seasons of 2002 and 2003.

\subsection{OTA formation by fungal isolates}

Black Aspergillus strains were plated on Czapek Yeast Agar (CYA) for OTA production assessment, according to the method proposed by Bragulat et al. (2001). Briefly, after 7 days of growth, 3 agar plugs were removed from a colony, and placed into a $4 \mathrm{ml}$ amber vial, and $500 \mu \mathrm{l}$ of methanol was added. After $60 \mathrm{~min}$, the extract was filtered and injected in the HPLC. Strains were considered positive for OTA production if the extract yielded a peak at a retention time similar to the OTA standard. The identity of OTA was confirmed, after derivatization with $\mathrm{BF}_{3}$ in methanol, as described in Serra et al. (2004). The detection limit of this method was $0.1 \mu \mathrm{g}$ OTA per $\mathrm{kg}$ of agar plugs.

The strains' ability to produce OTA was also assessed in natural grape juice medium (GJ50), prepared as follows: wine grapes were homogenized in a blender and centrifuged at $1100 \times g$. The supernatant was left to stabilize overnight at $4{ }^{\circ} \mathrm{C}$ and heated at $90{ }^{\circ} \mathrm{C}$ for $30 \mathrm{~min}$. Distilled water $(500 \mathrm{ml})$ with $4 \%(\mathrm{w} / \mathrm{v})$ agar was autoclaved at $121{ }^{\circ} \mathrm{C}$ for $15 \mathrm{~min}$ and $500 \mathrm{ml}$ of the wine grape juice was added. The mixture was heated at $105^{\circ} \mathrm{C}$ for $2 \mathrm{~min}$. Detection of OTA in the cultures was done as described above. For this study, 32 strains of $A$. carbonarius, 4 strains of A. ibericus, and 25 strains of the A. niger aggregate (being 10 OTA producers) were used. All these strains were isolated from grapes.

\subsection{Strain preservation}

The strains were preserved as a suspension of spores in $10 \%$ $(\mathrm{w} / \mathrm{w})$ glycerol solution $-80{ }^{\circ} \mathrm{C}$. They were deposited in the Micoteca da Universidade do Minho (MUM) culture collection.

\subsection{OTA detection in grapes}

Grapes were analysed according to Serra et al. (2004). The grapes (10 bunches) were homogenized, and an aliquot of $50 \mathrm{~g}$ was extracted with a $5 \%$ sodium bicarbonate and $1 \%$ polyethylene glycol solution. The mixture was centrifuged and the supernatant was applied to an immunoaffinity column (OchraTest, Vicam, Watertown, MA, USA). The columns were used according to the manufacturer instructions. OTA was eluted with HPLC grade methanol and quantified by reverse-phase HPLC using a fluorescent detector. The equipment used was a Jasco (Tokyo, Japan) FP-920 system set at $330 \mathrm{~nm}$ excitation wavelength and $460 \mathrm{~nm}$ emission wavelength. Chromatographic separations were performed on a Waters Spherisorb ODS2 $(4.6 \mathrm{~mm} \times 250 \mathrm{~mm} ; 5 \mu \mathrm{m})$ column (Alltech, Lexington, KY, USA), fitted with a pre-column with the same stationary phase operated at $30{ }^{\circ} \mathrm{C}$. The mobile phase was pumped at $1.0 \mathrm{ml} / \mathrm{min}$ and consisted of an isocratic programme as follows: acetonitrile:water:acetic acid (99:99:2, $\mathrm{v} / \mathrm{v})$. The injection volume was $100 \mu \mathrm{l}$. The limit of detection in grapes was $4 \mathrm{ng} / \mathrm{kg}$, and the average recovery rate was calculated as $76 \%$.

\subsection{Influence of grapes on OTA production}

OTA production ability of the $A$. carbonarius strain MUM03.59 (=01UAs263) was tested on homogenized wine grapes of 5 Portuguese grape varieties: Alvarinho and Loureiro, two white grape varieties originating from Vinhos Verdes; Tinta Barroca and Touriga Franca, red grape varieties originating from Douro; Vinhão, a red grape variety originating from Vinhos Verdes. Cabernet Sauvignon, the French red grape variety internationally used in winemaking, originating from 
Ribatejo, was used for comparative purposes. Grape samples at pea berry, early veraison and ripe berries were used. Homogenized wine grapes $(5 \mathrm{~g})$ were placed in universal 30 $\mathrm{ml}$ flasks and heated at $90{ }^{\circ} \mathrm{C}$ for $30 \mathrm{~min}$. From a 5-day-old culture grown in malt extract agar (MEA, Oxoid), a spore suspension was made in sterile water with $0.1 \%(\mathrm{w} / \mathrm{v})$ peptone. The suspension was washed 3 times, to remove residual OTA present in the spores, adjusted to a concentration of $10^{6}$ spores/ $\mathrm{ml}$ and used as inoculum $(100 \mu \mathrm{l})$. Inoculated flasks were incubated slanted to increase surface area for 7 days at $25{ }^{\circ} \mathrm{C}$ in the dark. The experiments were performed in triplicate. OTA extraction from medium and cultures in the flasks was made with chloroform (Abrunhosa et al., 2002), with the following modifications: the extraction was performed once and the OTA in $1 \mathrm{ml}$ of chloroform was quantified. Recovery experiments were performed using OTA-free homogenized grapes at the 3 maturation stages, spiked at 10, 100 and $1000 \mathrm{ng} / \mathrm{g}$. Recoveries averaged over six replicates.

\subsection{Determination of reducing sugars and total acidity in grapes}

The major variation in the chemical composition of grapes in the ripening process concerns reducing sugars and total acidity. The content of the samples in these parameters was determined by titration according to the methods described in UE Regulation No. 2676/90, 17 of September of 1990. Briefly, reducing sugars were determined by titration with a $0.1 \mathrm{M}$ sodium tiosulphate solution, after a cleaning procedure with a saturated lead acetate solution, followed by oxidation with an alkaline copper solution. Total acidity was determined by titration with a $0.1 \mathrm{M}$ sodium hydroxide.

\subsection{Statistical analysis}

Whenever variable distribution was not normal, the nonparametric test Kruskal-Wallis was used, with approximation to chi-square test as the hypothesis test. This was true for most variables, and in the absence of information about the test used, it was the treatment applied. Otherwise, the parametric test oneway analysis of variance (ANOVA) was applied, with Tukey honestly significantly difference (Tukey HSD) as post-hoc range test. Bivariate correlations with the Spearman correlation coefficient $\left(r_{\mathrm{s}}\right)$ were used to study linear relations between variables. The statistical analyses performed were considered significant when $P<0.05$. All statistic treatment was performed with the Statistic Package for Social Sciences $\left(\operatorname{SPSS}^{\circledR}\right)$ for Windows version 11.0.

\section{Results and discussion}

The frequency of occurrence of ochratoxigenic strains of black Aspergillus was correlated with the maturation of grapes (Table 1), the year of isolation and the vineyards (Table 2). A total of 92 black Aspergillus positive for OTA were isolated, being $74 \% \mathrm{~A}$. carbonarius strains and the remaining $26 \% \mathrm{~A}$. niger aggregate strains (Table 1).
Table 1

Number of black Aspergillus strains producing OTA isolated from grapes at different maturation stages

\begin{tabular}{llllll}
\hline Species & \multicolumn{3}{l}{ Number of ochratoxigenic strains } & $\begin{array}{l}\text { Percentage of } \\
\text { ochratoxigenic } \\
\text { strains }\end{array}$ \\
\cline { 2 - 5 } & $\begin{array}{l}\text { Pea } \\
\text { berry }\end{array}$ & $\begin{array}{l}\text { Early } \\
\text { veraison }\end{array}$ & $\begin{array}{l}\text { Ripe } \\
\text { berry }\end{array}$ & Total & \\
\hline A. carbonarius & $0(0)$ & $1(1)$ & $67(67)$ & $68(68)$ & 100 \\
aggregate A. niger & $0(45)$ & $3(113)$ & $21(413)$ & $24(571)$ & 4 \\
A. ibericus & 0 & $0(1)$ & $0(7)$ & $0(8)$ & 0 \\
A. aculeatus & 0 & $0(1)$ & 0 & $0(1)$ & 0 \\
A. japonicus & 0 & 0 & $0(2)$ & $0(2)$ & 0 \\
Percentage of & $0 \%$ & $4,4 \%$ & $95,6 \%$ & & \\
$\begin{array}{l}\text { ochratoxigenic } \\
\text { strains }\end{array}$ & & & & & \\
\hline
\end{tabular}

In brackets, the total number of black Aspergillus strains isolated at each stage.

In the 2001, 2002 and 2003 harvest seasons 49\%, 20\% and $31 \%$ of the positive OTA strains were isolated, respectively (Table 2). Nevertheless, the mean numbers of OTA producing strains found between years at harvest time did not differ significantly.

At pea berry, early veraison and ripe berry $0 \%, 4 \%$ and $96 \%$ of the positive OTA strains were isolated, respectively (Table 1). OTA producing fungi were detected without surface disinfection in 18 of the 32 grape samples taken at harvest time (56\%). OTA producing fungi were detected in all regions: Alentejo (4 positive samples out of 6), Douro (7 out of 9), Ribatejo (6 out of 9 ) and Vinhos Verdes (1 out of 8). The mean percentage of colonized berries with the fungi in the positive samples of Alentejo, Douro, Ribatejo and Vinhos Verdes was 14\%, 10\%, $8 \%$ and $2 \%$, respectively. The mean number of the OTA producing strains from Vinhos Verdes region was significantly lower than other regions $(P<0.05)$. Positive A. carbonarius strains were more equally distributed on the vineyards than $A$. niger aggregate. A. carbonarius was detected in all vineyards with the exception of vineyards 1 and 2. Positive A. niger aggregate strains were detected in the 3 Douro vineyards (4, 5 and 6) and additionally in one occasion at harvest time in the vineyards 9 and 11 . Vineyard 5 was the only place where OTA positive $A$. niger aggregate strains were found during the 3 harvest seasons, with $71 \%$ of the strains being isolated from this vineyard. A. carbonarius was isolated more frequently from the grapes of the southern regions of Alentejo and Ribatejo, from where 40 and $45 \%$ of the strains were isolated, respectively (Table 2).

The OTA content of grapes and the percentage of infection with OTA positive strains at ripe berry are presented in Table 3. OTA positive strains were found exclusively in 2 out of the 20 surface disinfected samples (10\%), which were identified as $A$. carbonarius in both cases. In 2002, fewer grapes samples had OTA. Also, the mean concentration of OTA in 2002 was significantly lower than in $2003(P<0.01)$. OTA was detected in $44 \%, 50 \%$ and $35 \%$ of the grape samples at pea berry, early veraison and ripe berry respectively, with mean OTA values of 263,149 , and $35 \mathrm{ng} / \mathrm{kg}$, respectively (Table 3 ). Nevertheless, significant statistical differences were not found between the OTA mean at the 3 maturation stages. There was no apparent 
Table 2

Number of black Aspergillus strains producing OTA isolated in each vineyard, from 2001 to 2003

\begin{tabular}{|c|c|c|c|c|c|c|c|c|}
\hline \multirow[t]{2}{*}{ Vineyard } & \multicolumn{4}{|c|}{$\mathrm{OTA}^{+} A$. niger aggregate } & \multicolumn{4}{|c|}{ A. carbonarius } \\
\hline & 2001 & 2002 & 2003 & Total & 2001 & 2002 & 2003 & Total \\
\hline 1 & 0 & 0 & 0 & 0 & 0 & 0 & 0 & 0 \\
\hline 2 & 0 & - & 0 & 0 & 0 & - & 0 & 0 \\
\hline 3 & 0 & 0 & 0 & 0 & 1 & 0 & 0 & 1 \\
\hline 4 & 0 & 1 & 0 & 1 & 4 & 3 & 0 & 7 \\
\hline 5 & 10 & 3 & 4 & 17 & 0 & 0 & 1 & 1 \\
\hline 6 & 1 & 0 & 0 & 1 & 0 & 0 & 1 & 1 \\
\hline 7 & 0 & 2 & 1 & 3 & 7 & 0 & 7 & 14 \\
\hline 8 & 0 & 0 & 0 & 0 & 1 & 2 & 7 & 10 \\
\hline 9 & 0 & 0 & 1 & 1 & 0 & 0 & 7 & 7 \\
\hline 10 & 0 & 0 & - & 0 & 1 & 2 & - & 3 \\
\hline 11 & 1 & 0 & 0 & 1 & 19 & 5 & 0 & 24 \\
\hline Total & 12 & 6 & 6 & & 33 & 12 & 23 & \\
\hline
\end{tabular}

relationship between the OTA content of grapes and the OTA positive fungi detected. A reason for this could rely on the fact that OTA formation by fungal isolates is being assessed in a synthetic medium, and not the natural substract. So, OTA production ability of 61 black Aspergillus strains in grape juice medium was tested. It was found out that all the positive strains on CYA were also positive on GJ50, and vice-versa. However, the levels of OTA produced on the grape juice medium are lower than the levels produced on CYA. The use

Table 3

Ochratoxin A content of grape samples from 2002 to 2003 and infection with OTA producing strains at ripe berry

\begin{tabular}{|c|c|c|c|c|c|}
\hline \multirow[t]{2}{*}{ Vineyard } & \multirow[t]{2}{*}{ Year } & \multirow{2}{*}{$\begin{array}{l}\begin{array}{l}\text { Pea } \\
\text { berry }\end{array} \\
\text { OTA } \\
(\mathrm{ng} / \mathrm{kg})\end{array}$} & \multirow{2}{*}{$\begin{array}{l}\begin{array}{l}\text { Early } \\
\text { veraison }\end{array} \\
\text { OTA } \\
(\mathrm{ng} / \mathrm{kg})\end{array}$} & \multicolumn{2}{|l|}{ Ripe berry ${ }^{a}$} \\
\hline & & & & $\begin{array}{l}\text { OTA } \\
(\mathrm{ng} / \mathrm{kg})\end{array}$ & $\begin{array}{l}\text { Infection with } \\
\text { OTA }^{+} \text {fungi }{ }^{\mathrm{b}}(\%)\end{array}$ \\
\hline 1 & 2002 & $<\mathrm{LOD}$ & 8.2 & 36.0 & 0 \\
\hline 1 & 2003 & $<$ LOD & 470.2 & 42.9 & 0 \\
\hline 2 & 2002 & $<\mathrm{LOD}$ & $<\mathrm{LOD}$ & Not tested & Not tested \\
\hline 2 & 2003 & 32.4 & 13.0 & $<\mathrm{LOD}$ & 0 \\
\hline 3 & 2002 & $<\mathrm{LOD}$ & $<\mathrm{LOD}$ & $<\mathrm{LOD}$ & 0 \\
\hline 3 & 2003 & 56.5 & $<\mathrm{LOD}$ & $<$ LOD & 0 \\
\hline 4 & 2002 & $<$ LOD & 10.2 & $<$ LOD & 0 \\
\hline 4 & 2003 & 42.0 & 912.7 & $<\mathrm{LOD}$ & 0 \\
\hline 5 & 2002 & $<$ LOD & $<\mathrm{LOD}$ & $<$ LOD & 0 \\
\hline 5 & 2003 & 14.1 & 45.0 & $<\mathrm{LOD}$ & 0 \\
\hline 6 & 2002 & $<$ LOD & $<\mathrm{LOD}$ & $<$ LOD & 0 \\
\hline 6 & 2003 & 104.2 & $<\mathrm{LOD}$ & $<\mathrm{LOD}$ & 0 \\
\hline 7 & 2002 & $<\mathrm{LOD}$ & $<\mathrm{LOD}$ & $<$ LOD & 0 \\
\hline 7 & 2003 & 159.3 & 11.3 & 11.0 & 0 \\
\hline 8 & 2002 & $<\mathrm{LOD}$ & $<\mathrm{LOD}$ & 61.4 & 0 \\
\hline 8 & 2003 & 58.2 & 7.7 & 10.0 & 0 \\
\hline 9 & 2002 & $<$ LOD & 110.6 & 56.3 & 0 \\
\hline 9 & 2003 & 1637.6 & 11.7 & 24.0 & 4 \\
\hline 10 & 2002 & Not tested & $<$ LOD & $<$ LOD & 2 \\
\hline 10 & 2003 & Not tested & 33.8 & Not tested & Not tested \\
\hline 11 & 2002 & Not tested & $<\mathrm{LOD}$ & $<$ LOD & 0 \\
\hline 11 & 2003 & Not tested & $<\mathrm{LOD}$ & $<$ LOD & 0 \\
\hline Mean OTA value & 363 & 149 & 35 & & \\
\hline
\end{tabular}

${ }^{\text {a }}<\mathrm{LOD}=$ below detection limit of $4 \mathrm{ng} / \mathrm{kg}$.

${ }^{\mathrm{b}}$ Percentage of berries where the OTA positive fungi were detected after surface disinfection.
Table 4

OTA production by A. carbonarius strain MUM03.59 in 5 Portuguese grape varieties and Cabernet Sauvignon at pea berry, early veraison and ripe berry

\begin{tabular}{llcl}
\hline Grape variety & \multicolumn{2}{l}{ OTA $(\mu \mathrm{g} / \mathrm{kg})$} & \\
\cline { 2 - 4 } & Pea berry & Early veraison & Ripe berry \\
\hline Alvarinho & $1629 \pm 379$ & $68 \pm 23$ & $12 \pm 10$ \\
Loureiro & $3346 \pm 795$ & $32 \pm 17$ & Not tested \\
Vinhão & $5244 \pm 3785$ & $212 \pm 65$ & $51 \pm 13$ \\
Tinta Barroca & $3387 \pm 968$ & $5781 \pm 2445$ & $13^{\mathrm{a}}$ \\
Touriga Franca & Not tested & $2892 \pm 169$ & $15 \pm 7$ \\
Cabernet Sauvignon & Not tested & $194 \pm 48$ & $15 \pm 2$ \\
\hline
\end{tabular}

a One sample only; excluded from statistical analysis.

of CYA was as effective as GJ50 for evaluating OTA detection.

The influence of the composition of different grape varieties at different maturation stages on OTA production by $A$. carbonarius strain MUM03.59 was investigated. The recovery rates of the method used to analyse OTA production in grapes with spiked grape samples at 10,100 and $1000 \mu \mathrm{g} / \mathrm{kg}$ were $56.9 \%, 74.8 \%$ and $79.8 \%$, respectively. Relative standard deviations at 10,100 and $1000 \mu \mathrm{g} / \mathrm{kg}$ were $24.3 \%, 4.9 \%$ and $8.1 \%$, respectively. The OTA production results of $A$. carbonarius MUM03.59 in grapes are presented in Table 4.

OTA production was significantly different between all stages $(P<0.001)$, with a mean value at pea berry, early veraison, and ripe berry of 3402,1530 , and $22 \mu \mathrm{g} / \mathrm{kg}$, respectively. Mitchell et al. (2004) investigated OTA production by this strain (MUM03.59=01UAs263=Port2) in a synthetic grape juice medium representative of grape composition at early veraison. The OTA produced at $20^{\circ} \mathrm{C}$ between 0.95 and $0.98 a_{\mathrm{w}}$ in the mentioned medium was in the same magnitude order than the values here reported for natural homogenized grapes at early veraison stage.

Table 5

Reducing sugars and total acidity of the grape varieties used to test OTA production at pea berry, early veraison and ripe berry

\begin{tabular}{llll}
\hline Grape variety & Maturation stage & Total acidity $^{\mathrm{a}}(\mathrm{g} / \mathrm{l})$ & Reducing sugars $(\mathrm{g} / \mathrm{l})$ \\
\hline Alvarinho & Pea berry & Not tested & Not tested \\
& Early veraison & 9.4 & 166.5 \\
& Ripe berry & 6.0 & 210.1 \\
Loureiro & Pea berry & 17.2 & 7.4 \\
& Early veraison & 7.9 & 179.2 \\
\multirow{5}{*}{ Vinhão } & Ripe berry & 5.2 & 205.0 \\
& Pea berry & Not tested & Not tested \\
& Early veraison & 16.1 & 131.3 \\
Tinta Barroca & Ripe berry & 7.5 & 231.0 \\
& Pea berry & 25.1 & 6.2 \\
& Early veraison & 13.1 & 106.6 \\
Touriga Franca & Ripe berry & 2.4 & 268.0 \\
& Pea berry & 21.8 & 5.0 \\
Cabernet & Early veraison & 20.6 & 41.4 \\
Sauvignon & Ripe berry & 2.8 & 253.4 \\
& Pea berry & Not tested & Not tested \\
& Early veraison & Not tested & Not tested \\
\hline
\end{tabular}

${ }^{\mathrm{a}}$ Expressed in $\mathrm{g} / \mathrm{l}$ of tartaric acid. 
No significant differences were found with the ANOVA statistic test at pea berry stage. However, at early veraison, significant differences were found between the composition of different grape varieties $(P<0.01)$, with the mean OTA production being higher in the Douro varieties Tinta Barroca and Touriga Franca and lowest in Loureiro. At ripe berry, significant differences were detected using the ANOVA test $(P<0.01)$, with the mean OTA production in Vinhão being higher than in the other grape varieties.

The differences found in OTA production with the composition of different grape varieties and with the maturation stage are supported by the total acidity and reducing sugars content of grapes (Table 5). OTA production by A. carbonarius was maximal in the samples with highest total acidity content and lowest reducing sugar values. This was supported by statistical analysis, with the production of OTA by $A$. carbonarius being significantly positively and negatively correlated with the total acidity of grapes $\left(r_{\mathrm{s}}=0.855, P<0.001\right)$ and reducing sugars content $\left(r_{\mathrm{s}}=-0.835, P<0.001\right)$, respectively.

\section{Conclusions}

The results obtained in the 3 years of study allowed drawing the same conclusions in terms of OTA producing fungi. The maturation stage of grapes influenced the incidence of OTA producing fungi, with near $96 \%$ of the OTA producing strains being detected at harvest time. A. carbonarius was the OTA producing species more abundant and widespread in the vineyards, while $A$. niger aggregate was found mainly in one vineyard. Nevertheless, OTA synthesis was found to occur in grapes since the earliest maturation stages, and was detected in all the maturation stages. The composition of grapes in different maturation stages highly influenced OTA production by the A. carbonarius strain tested, with OTA production being favoured with higher contents of organic acids and lower contents of reducing sugars. The moment of infection by OTA producing fungi of grapes may be determinant for the final OTA content. The importance of minimizing damage in grape berries is emphasised from the earliest stages of maturation until harvest and grape transportation to the processing place. The OTA levels detected in Portuguese grapes at all stages were always below the maximum limit for OTA in wine of $2 \mu \mathrm{g} / \mathrm{kg}$. In the light of these results, and in line with the results on OTA content of Portuguese wines (Ratola et al., 2004) and European Portuguese OTA intake estimates (Miraglia and Brera, 2002), it appears that the mycotoxin eventually found in Portuguese wine does not present a significant hazard to consumers.

\section{Acknowledgments}

The authors gratefully acknowledge the support of the EC, Quality of Life Programme (QoL), Key Action 1 (KA1) on Food, Nutrition and Health; contract number QLK1-CT-200101761 - Wine-Ochra Risk. R. Serra was supported by grant SFRH/BPD/2827/2004 from Fundação para a Ciência e Tecnologia.

\section{References}

Abrunhosa, L., Serra, R., Venâncio, A., 2002. Biodegradation of ochratoxin A by fungi isolated from grapes. Journal of Agricultural and Food Chemistry 50, 7493-7496

Battaglia, R., Hatzold, T., Kroes, R., 1996. Conclusions from the Workshop on ochratoxin in food, organized by ILSI Europe in Aix-en-Provence (10-12 January 1996). Food Additives and Contaminants 13, 1-3.

Battilani, P., Giorni, P., Pietri, A., 2003. Epidemiology of toxin-producing fungi and ochratoxin A occurrence in grape. European Journal of Plant Pathology 109, 715-722.

Belli, N., Ramos, A.J., Sanchis, V., Marin, S., 2004. Incubation time and water activity effects on ochratoxin A production by Aspergillus Section Nigri strains isolated from grapes. Letters in Applied Microbiology 38, $72-77$.

Bragulat, M.R., Abarca, M.L., Cabañes, F.J., 2001. An easy screening method for fungi producing ochratoxin A in pure culture. International Journal of Food Microbiology 71, 139-144.

Burdaspal, P.A., Legarda, T.M., 1999. Ochratoxina A en vinos, mostos y zumos de uva elavorados en España y en otros paises europeos. Alimentaria 107-113 (Enero-Febrero).

Miraglia, M., Brera, C., 2002. Assessment of dietary intake of ochratoxin A by the population of EU member states. Report on Tasks for Scientific Cooperation. Directorate-General Health and Consumer Protection.

Mitchell, D., Parra, R., Aldred, D., Magan, N., 2004. Water and temperature relations of growth and ochratoxin A production by Aspergillus carbonarius strains from grapes in Europe and Israel. Journal of Applied Microbiology 97, 439-445.

Otteneder, H., Majerus, P., 2000. Occurrence of ochratoxin A (OTA) in wines: influence of the type of wine and its geographical origin. Food Additives and Contaminants 17, 793-798.

Pietri, A., Bertuzzi, T., Pallaroni, L., Piva, G., 2001. Occurrence of ochratoxin A in Italian wines. Food Additives and Contaminants 18, 647-654.

Pitt, J.I., Hocking, A.D., 1997. Fungi and Food Spoilage, 2nd ed. Blackie Academic and Professional, London.

Ratola, N., Martins, L., Alves, A., 2004. Ochratoxin A in wines - assessing global uncertainty associated with the results. Analytica Chimica Acta 513, 319-324.

Serra, R., Abrunhosa, L., Kozakiewicz, Z., Venâncio, A., 2003. Black Aspergillus species as ochratoxin A producers in Portuguese wine grapes. International Journal of Food Microbiology 88, 63-68.

Serra, R., Mendonca, C., Abrunhosa, L., Pietri, A., Venâncio, A., 2004. Determination of ochratoxin A in wine grapes: comparison of extraction procedures and method validation. Analytica Chimica Acta 513, 41-47.

Serra, R., Braga, A., Venâncio, A., 2005. Mycotoxin producing and other fungi isolated from grapes for wine production with particular emphasis on ochratoxin A. Research in Microbiology 156, 515-521.

Serra, R., Cabañes, F. J., Perrone, G., Castellá, G., Venâncio, A., Mulè, G., Kozakiewicz, Z., in press. Aspergillus ibericus: a new species of the section Nigri isolated from grapes, Mycologia.

Soufleros, E.H., Tricard, C., Bouloumpasi, E.C., 2003. Occurrence of ochratoxin A in Greek wines. Journal of the Science of Food and Agriculture 83, 173-179.

Stefanaki, I., Foufa, E., Tsatsou-Dritsa, A., Dais, P., 2003. Ochratoxin A concentrations in Greek domestic wines and dried vine fruits. Food Additives and Contaminants 20, 74-83.

Walker, R., 1999. Mycotoxins of growing interest. Presented at the 3rd Joint FAO/UNEP International Conference on Mycotoxins, Tunis, Tunisia, March $3-6$.

Zimmerli, B., Dick, R., 1995. Determination of ochratoxin A at the ppt level in human blood, serum, milk and some foodstuffs by HPLC with enhanced fluorescence detection and immunoaffinity column clean-up methodology and Swiss data. Journal of Chromatography, B 666, 85-89.

Zimmerli, B., Dick, R., 1996. Ochratoxin A in table wine and grape juice: occurrence and risk assessment. Food Additives and Contaminants 13, $655-668$. 